\title{
Mediación e inmediatez en la Dialéctica negativa de Theodor W. Adorno
}

\author{
Mediation and immediacy \\ in Adorno's Negative dialectic
}

\author{
EDUARDO ASSALONE \\ Consejo Nacional de Investigaciones Científicas y Técnicas \\ Universidad Nacional de Mar del Plata (Argentina)
}

\section{RESUMEN}

En el presente trabajo se realiza una presentación de los conceptos y categorías principales de la Segunda Parte de Dialéctica negativa de Theodor W. Adorno. A partir de dicha presentación se plantean una serie de críticas a la posición de Adorno con el fin de demostrar la necesidad de reconocer un nivel inmediato de la realidad en base al cual actúen las diferentes mediaciones dialécticas. Al mismo tiempo, se señala la posibilidad de hacer esto dentro del propio marco de la dialéctica negativa, como una radicalización de la misma, en la tradición dialéctica inaugurada por Hegel.

\author{
PLABRAS CLAVE
}

ADORNO, HEGEL, DIALÉCTICA NEGATIVA, MEDIACIÓN/INMEDIATEZ

\begin{abstract}
This paper gives a presentation of the main concepts and categories of Part II of Negative dialectics by Theodor W. Adorno. As from this presentation a series of criticisms to Adorno's
\end{abstract}


position is offered in order to demonstrate the need of acknowledging an immediate level of reality which is at the basis of the action of different dialectical mediations. At the same time the possibility of doing this inside the limits of the negative dialectics is explained as a radicalization of it in the dialectical tradition inaugurated by Hegel.

KEYWORDS

ADORNO, HEGEL, NEGATIVE DIALECTICS, MEDIATION/IMMEDIACY

\section{INTRODUCCIÓN}

UNA DE LAS INTUICIONES FILOSÓFICAS MÁS PODEROSAS de la filosofía hegeliana es aquella que produce una verdadera transvaloración en el campo de la teoría del conocimiento. Me refiero a la producción de una doble inversión en el lenguaje gnoseológico tradicional: 1) lo concreto se vuelve abstracto; y 2) el saber absoluto no es inmediato sino mediado. Por una parte, lo que tenemos comúnmente por lo más cierto, lo más concreto, esto es, los datos empíricos en su dimensión más sensorial, es por el contrario lo más abstracto, lo más indeterminado, lo más pobre en términos de conocimiento. Como dice Hegel en la Fenomenología del espíritu respecto de la certeza sensible -donde tenemos un esto (lo sentido, el objeto) y un éste (quien siente, el yo)-: «Al decir este aquí, este ahora, algo singular, digo todos los estos, los aquí, los ahora, los singulares; y lo mismo, al decir yo digo este yo singular, digo en general, todos los yo; cada uno de ellos es lo que digo: yo, este yo singular». ${ }^{1}$ Lejos de ser lo más concreto, cierto, rico y verdadero, el «aquí y ahora» del esto singular, de la impresión sensible, es, en realidad, una pura abstracción indeterminada, el conocimiento más pobre, lo más ambiguo: en la palabra «esto» cabe todo ser.

Por otra parte, el saber absoluto, por absoluto, no implica el carácter de inmediato. O, a la inversa, un conocimiento, por inmediato, no necesariamente será también absoluto. Por el contrario, el saber absoluto en el sistema hegeliano, el término de la experiencia de la conciencia, el punto culminante del proceso desde el punto de vista gnoseológico, es lo más mediado, lo más concreto, rico en determinaciones laboriosamente ganadas mediación tras mediación. Si la primera inversión -la que sostiene que lo pretendidamente más concreto es en realidad lo más abstracto- es una crítica directa al empirismo (el de Hume, el de Kant inclusive), la segunda inversión -que disocia lo absoluto de lo inmediato y

1 G.W.F. Hegel, Fenomenología del espíritu, tr. Wenceslao Roces, México: FCE, 2006, p. 66 . 
hace, por tanto, del saber absoluto el punto máximo de mediatización- apunta más bien al intuicionismo racionalista que gozaba de buena salud, en tiempos de Hegel, en las filosofías de Jacobi y de Schelling. ${ }^{2}$ Hegel -como Kant décadas antes de él-quiso sortear la dicotomía empirismo/racionalismo que dividió aguas en la filosofía moderna, y supo hacerlo -también como Kant- negando tanto el status privilegiado que le había dado el empirismo a las sensaciones, como negando, al mismo tiempo, la posibilidad misma, para los seres racionales no divinos, de una «intuición intelectual» que nos permitiera conocer sin ningún tipo de mediaciones.

Pues bien, estos son los orígenes de la tradición en la que se inscribe la obra de madurez de Theodor Adorno, Dialéctica negativa (en adelante, DN), de $1966 .{ }^{3} \mathrm{El}$ «empirismo» será, en el contexto del siglo XX, el positivismo y el empirismo lógicos; el «intuicionismo», la fenomenología de Husserl y la ontología de Heidegger. Contra ambas tradiciones filosóficas delineó su dialéctica negativa, en el marco de una crítica inmanente a la tradición de la filosofía clásica alemana, el idealismo desde Kant hasta Schelling y que alcanza su acmé en la obra de Hegel. El materialismo marxiano le dará la pauta de cómo llevar a cabo tamaño programa.

De las dos inversiones hegelianas mencionadas me concentraré aquí en la segunda de ellas, en la que se sospecha del carácter inmediato de lo que consideramos «dado» u «objetivo» (esto es, aquello que no habría sufrido la intervención del sujeto). En DN, Adorno sostiene que el ente (Seiende) no es inmediatamente, sino sólo a través del concepto, y que, en consecuencia, es necesario comenzar a pensar desde éste y no a partir del mero dato - aún cuando, como veremos inmediatamente, el algo (Etwas) sea el punto de partida. Esto le permite criticar, sobre todo, la concepción positivista clásica de los «hechos» como lo dado, completamente independiente de quienes los investigan. También la afirmación de que no hay nada que no esté mediado de alguna forma está a

2 Véase: Jorge Dotti,Dialéctica y Derecho. El proyecto ético-político hegeliano, Buenos Aires: Hachette, 1983, pp. 29 y ss.

3 Según indica Carlos E. Massé Narváez, es a través de Lukács que Adorno se acerca al pensamiento de Hegel: «[...] se puede identificar la influencia primigenia de Kant en el pensamiento de Adorno; pero también Hegel dejó sentir su influencia, aunque inicialmente de manera indirecta, pues según se refiere, fue la lectura de Historia y conciencia de clase, de Lukács, la que parece que mediante el marxismo hegelianizado, permitió a Adorno acercarse a éste pensador». Véase: Carlos E. Massé Narváez, «Adorno. Teoría crítica y dialéctica negativa», en: Revista de Antropología Experimental, $\mathrm{N}^{\circ}$ 4, 2004, Universidad de Jaén (España), p. 2 (véase también: Ibid., p. 4). De todas maneras, el lugar más claro donde Adorno señala su adscripción a la tradición hegeliana es la obra Drei Studien zu Hegel. Véase especialmente: Theodor W. Adorno, Tres estudios sobre Hegel, tr. Víctor Sánchez de Zavala, Madrid: Taurus, 1974, «Aspectos» (1956). 
la base de una de las críticas que Adorno dirige a la fenomenología de Husserl y a la ontología de Heidegger: el objeto o el «ser» no son inmediatos.

A partir de esta presentación de la Segunda Parte de $D N$ que realizo aquí, plantearé una serie de críticas a la posición de Adorno con el fin de demostrar la necesidad de reconocer una instancia inmediata de la realidad en base a la cual actúen las diferentes mediaciones dialécticas. Al mismo tiempo, señalo la posibilidad de hacer esto dentro del propio marco de la dialéctica negativa sin necesidad de asumir posiciones positivistas, fenomenológicas u ontológicas (en el estilo de Heidegger). En este sentido, el presente trabajo ha sido estructurado en dos partes. En la primera de ellas se exponen algunas de las ideas principales de la dialéctica negativa con el fin de contextualizar las críticas que se desarrollan en la segunda parte de este trabajo.

\section{DiALÉCTICA NEGATIVA: CONCEPTO Y CATEGORÍAS}

En esta primera parte del trabajo ofreceré un resumen de las principales ideas expuestas en la Segunda Parte de $D N$, sección titulada «Dialéctica negativa. Concepto y categorías», según el orden en que aparecen en dicha obra. Dichas ideas principales pueden agruparse en siete unidades, en las cuales se desarrollan los siguientes temas y problemas: 1) el algo como punto de partida; 2) la contrariedad objetiva; 3) la no-inmediatez; 4) los dualismos resignificados; 5) la abstracción y el canje; 6) la preponderancia del objeto; 7) el materialismo dialéctico (el orden de esta enumeración corresponde al desarrollo argumental de la Segunda Parte de $D N$ ). Por motivos de extensión, no me ocuparé aquí de los ítems 4), 5) y 7), que no serán especialmente requeridos como referencia de los argumentos vertidos en la segunda parte de este trabajo. ${ }^{4}$

4 Para el ítem 4), véase: Theodor W. Adorno, Dialéctica negativa, Obra completa, vol. 6, tr. Alfredo Brotons Muñoz, Madrid: Akal, 2008 (en adelante, $D N$ ), pp. 160 y ss. He cotejado esta versión en español de Dialéctica negativa con el original: Theodor W. Adorno, Negative Dialektik, Frankfurt am Main: Suhrkamp Verlag, 1966. Para el ítem 5), véase: $D N$, pp. 170-171; S. Buck-Morss, op . cit., p. 74; Fredric Jameson, Marxismo tardío. Adorno y la persistencia de la dialéctica, tr. María Julia De Ruschi, Buenos Aires: FCE, 2010, pp. 46 y 47. Para el ítem 7), véase: DN, pp. 182 y ss, 191; Javier Hernández-Pacheco, «Abstracción y negatividad. La idea de una dialéctica negativa como crítica del idealismo en Th. W. Adorno», en: Themata. Revista de Filosofía, Núm. 3, 1986, pp. 63-64. Cf la concepción del materialismo adorniano que presenta Simon Jarvis: «Para Adorno mismo, querer ser materialista significa partir, no de un conjunto de compromisos metafísicos o metodológicos fijos, sino de algo que podría ser denominado más acertadamente un impulso [impulse]: el deseo utópico de felicidad no ilusoria, incluido el placer corporal, el deseo de un fin del sufrimiento. Este deseo puede ser simple, incluso ingenuo, pero requiere toda la astucia del artificio filosófico 


\section{II.1. EL ALGO}

La primera proposición de la Segunda Parte de DN, reza así: «Kein Sein ohne Seiendes»: «Ningún ser sin el ente». El «algo» (Etwas), no el «ser» (Sein), es nuestro punto de partida. Con este gesto inaugural, Adorno cuestiona la ontología hegeliana:

En la primera nota a la primera tríada de la Lógica, Hegel se niega a comenzar por el algo en lugar de por el ser... Con ello prejuzga toda la obra, que quiere exponer la primacía del sujeto, en el sentido de éste, idealistamente. [...] [E]n el arranque de la Lógica Hegel no puede soportar siquiera el mínimo vestigio de no-identidad que la palabra «algo» recuerda. ${ }^{5}$

Esto también lo diferencia de la ontología de Heidegger, a la que critica duramente en la sección inmediatamente anterior de $D N$ : si bien Heidegger (siguiendo el programa de Husserl de volver «a las cosas mismas») va a pensar también lo existente más allá de la determinación del sujeto, lo que hace es volver al dualismo de la prima philosophia: hay una instancia primaria, «el ser», y una instancia secundaria y subordinada, «el ente». La diferencia «óntico/ ontológico» subordina el Seiende al Sein (como en Hegel). Sin embargo, para Adorno, el Sein es una abstracción del Seiende, no su ser auténtico. Contrariamente a lo que puede inducirnos a pensar la morfología de estos términos, lo que es no presupone el ser, sino que el ser es una derivación conceptual de un algo (de muchos «algos») concreto existente. Lo que Adorno quiere impugnar aquí es la antigua operación filosófica característica de la metafísica: «Donde se enseña algo absolutamente primero, siempre se habla, como de un correlato conforme a sentido, de algo inferior, absolutamente heterogéneo con respecto a él; la prima philosophia y el dualismo van juntos». ${ }^{6}$

No obstante las observaciones mencionadas a la lógica hegeliana y a la ontología heideggeriana, el programa filosófico que pone como primer punto el comenzar por el objeto, es un rasgo coincidente entre la fenomenología husserliana, la ontología de Heidegger e incluso el positivismo. Todo pensamiento (sujeto) presupone necesariamente un algo sobre lo cual piensa (objeto). Pero, ¿de

si no ha de ser deformado, vuelto una parodia de sí mismo, desde el principio. Adorno parte de una aguda conciencia de cuán difícil es ser materialista. Cuanto más rápida y brutalmente el pensamiento se desliga de la ilusión, más se enreda». Simon Jarvis, «Adorno, Marx, Materialism», en: Tom Huhn (ed.), The Cambridge Companion to Adorno, Cambridge: Cambridge University Press, 2006, Chapter 3, p. 80. Para la cuestión de la felicidad en el pensamiento de Adorno y su relación con Hegel, véase: Silvia Schwarzböck, Adorno y lo político, Buenos Aires: Prometeo, 2008.

5 DN, p. 133n.

6 Ibid., p. 136. 
qué clase es la relación entre sujeto y objeto en la $D N$ de Adorno? Precisamente esa relación es «dialéctica» y «negativa». Dice Susan Buck-Morss:

Adorno no afirmaba ni el concepto ni la realidad en sí mismos. En cambio planteaba cada uno en crítica referencia al otro. Dicho de otro modo, cada uno era afirmado sólo en su no identidad respecto del otro. En realidad, el «principio de no identidad», que Adorno desarrollaría con riqueza creciente, llegó a ser el fundamento de su filosofía, es decir, de la «dialéctica negativa».

Esto marca una diferencia rotunda con el idealismo, pues éste, en sus diversas formas, afirma la identidad de sujeto y objeto; en verdad, lo que hace es subsumir el objeto en el sujeto (es pura representación suya, como en Kant, o es lo real que es idéntico a lo racional, en Hegel). Pero, advertirá Adorno en clave marxista: «la subjetividad, el pensar mismo, no cabe explicarla por sí, sino a partir de lo fáctico, sobre todo de la sociedad». ${ }^{8}$ Ahora las diferencias se evidencian en relación con el positivismo, para el cual la dialéctica es una quimera: el positivista, aunque admite sin reservas la preeminencia del objeto (los «hechos»), no encuentra en éste la necesaria mediación del concepto (del sujeto) para el conocimiento. No ve la relación dialéctica entre objeto y sujeto: la objetividad no existe tampoco sin la subjetividad.

Tenemos aquí, entonces, una primera aproximación a la concepción adorniana de la mediación (Vermittlung): el sujeto está siempre-ya mediado (negativamente) por el objeto, pero a su vez éste se encuentra siempre-ya mediado (negativamente) por el sujeto. La inmediatez (Unmittelbarkeit) del objeto no es tal: supone la mediación del concepto. Al mismo tiempo, como expresa Esther Barahona Arriaza, el «concepto no es [...] algo inmediato, sino mediado y mediado por un componente irracional -la realidad-, que es precisamente lo que sobrevive en él gracias al significado». Y agrega: «El concepto siempre significa más de lo que dice; el concepto supera al concepto».9

\section{II.2. LA CONTRARIEDAD OBJETIVA}

La relación de mediación entre sujeto y objeto es de «contrariedad objetiva»: «lo irritante de la dialéctica», dice Adorno, «es la contrariedad objetiva

7 Susan Buck-Morss, Origen de la dialéctica negativa. Theodor W. Adorno, Walter Benjamin y el Instituto de Frankfurt, tr. Nora Rabotnikof Maskivker, México: Siglo XXI, 1981, p. 139.

8 DN, p. 137.

9 Esther Barahona Arriaza, «Categorías y modelos en la Dialéctica negativa de Th. W. Adorno: crítica al pensamiento idéntico», en: Logos. Anales del Seminario de Metafísica, vol. 39, 2006, p. 210. 
[objektive Widersprü̈chlichkeit]». ${ }^{10}$ Esto no debería sorprendernos, pues ya en Hegel las mediaciones son formas de contrariedad, de negatividad. Como puede leerse en el Prólogo de la Fenomenología del espíritu:

La sustancia viva es, además, el ser que es en verdad sujeto o, lo que tanto vale, que es en verdad real, pero sólo en cuanto es el movimiento de ponerse a sí misma [Sich-selbst-setzens] o la mediación de su devenir otro consigo misma [Vermittlung des Sich-anders-werdens]. Es, en cuanto sujeto, la pura y simple negatividad y es, cabalmente por ello, el desdoblamiento de lo simple o la duplicación que contrapone, que es de nuevo la negación de esta indiferente diversidad y de su contraposición [Gegensatzes]: lo verdadero es solamente esta igualdad que se restaura o la reflexión en el ser otro en sí mismo, y no una unidad originaria en cuanto tal o una unidad inmediata [unmittelbare] en cuanto tal. ${ }^{11}$

O como dice Hegel una página después: «En efecto, la mediación [Vermittlung] no es sino la igualdad consigo misma [Sichselbstgleichheit] en movimiento o la reflexión en sí misma, el momento del yo que es para sí, la pura negatividad o, reducida a su abstracción pura, el simple devenir. El yo o el devenir en general, este mediar [Vermitteln], es cabalmente, por su misma simplicidad, la inmediatez que deviene [die werdende Unmittelbarkeit] y lo inmediato [das Unmittelbare] mismo». ${ }^{12}$ Como puede verse con claridad en estas dos citas, Hegel piensa en términos de negatividad -y de subjetividad, pues la negación es una actividad propia del sujeto, o de la sustancia en su devenir sujeto- la mediación dialéctica. Se trata de un movimiento de auto-contraposición del sujeto por medio del cual éste «dialectiza» la inmediatez, la hace devenir otra consigo misma. Lo que no admite Adorno es la «restauración» de la identidad del sujeto respecto a sí mismo. Si bien acepta plenamente que lo verdadero no consiste en una «una unidad originaria en cuanto tal o una unidad inmediata en cuanto tal», no deduce de ello que lo verdadero sea «solamente esta igualdad que se restaura o la reflexión en el ser otro en sí mismo», como expresa Hegel en la primera de las citas. Dicho en otras palabras, la mediación del sujeto por el objeto y del objeto por el sujeto no es un movimiento negativo del sujeto respecto a sí mismo, una contraposición donde los términos son ambos subjetivos, sino que, por el contrario, la negatividad dialéctica que hace devenir otro a lo inmediato confirma la no-identidad entre los términos contrapuestos: el sujeto es lo que no es el objeto y el objeto es lo que no es el sujeto. No hay igualdad que pueda restaurarse porque sencillamente no hay tal igualdad o identidad.

10 DN, p. 147

11 G.W.F. Hegel, op. cit., pp. 15-16.

12 Ibid., p. 17. 
La contrariedad es «objetiva» no sólo porque, como acabo de decir, no consiste en un movimiento del sujeto consigo mismo, sino también porque se da en la realidad objetiva: se trata de la sociedad capitalista como esencialmente antagónica. Expresa Adorno a este respecto: «Pero la contrariedad objetiva no designa solamente lo que del ente [objeto] queda fuera en el juicio [sujeto], sino algo en lo juzgado mismo. Pues el juicio siempre significa el ente por juzgar más allá de aquello particular incluido en el juicio; de otro modo, sería, por su propia intención, superfluo». ${ }^{13}$ Como dice Alberto Bonnet:

La dialéctica negativa aspira [...] a guardar una suerte de fidelidad a ese carácter antagónico de la sociedad capitalista: es una modalidad de pensamiento dialéctica porque la sociedad es antagónica, y negativa porque dicho antagonismo no puede superarse por medio del pensamiento, y utópica, ciertamente, porque sigue aspirando a una realidad reconciliada. ${ }^{14}$

[L]a fidelidad a esa utopía exige, en la dialéctica negativa, un rechazo de cualquier intento de emancipar la diferencia respecto de la negatividad en el plano del concepto (de la dialéctica), toda vez que esa emancipación no hay tenido lugar en el plano del objeto (de la sociedad). ${ }^{15}$

De todas maneras, la contrariedad objetiva no se agota en el antagonismo social intrínseco a la sociedad capitalista. También se da al interior del propio pensamiento, en el concepto; precisamente la «dialéctica» da cuenta de este carácter contradictorio del concepto en sí mismo. Asimismo, hay una forma más de contradicción y es la que se establece entre realidad y concepto: el sujeto, como individuo, está sometido a la dominación del «objeto»-entendido como «totalidad» (el «sistema» social). Estos tres tipos de contradicción -contradicción en el objeto, contradicción entre objeto y sujeto y contradicción en el sujeto- son todas formas de no-identidad dialéctica. Y esta no-identidad, a su vez, es una forma de mediación: una mediación que, aunque dialéctica como en Hegel, no consiste en una restauración identificadora sino, por el contrario, es negatividad pura: la contradicción.

13 DN, p. 147.

14 Alberto R. Bonnet, «Antagonismo y diferencia: la dialéctica negativa y el posestructuralismo ante la crítica del capitalismo contemporáneo», en: John Holloway, Fernando Maramoros y Sergio Tischler (compiladores), Negatividad y revolución. Theodor W. Adorno y la política, Buenos Aires: Herramienta; México: Universidad de Puebla, 2007, p. 40.

15 Ibid., p. 66. 


\section{II.3. LA NO INMEDIATEZ}

«Puesto que el ente no es inmediatamente, sino sólo a través del concepto, habría que comenzar por el concepto, no por el mero dato». ${ }^{16}$ Esto invierte el propio comienzo que propuso Adorno. Podríamos decir que en el orden ontológico lo primero es el ente, el algo sobre el cual se juzga; pero en el orden gnoseológico, por el contrario -dentro ya del juicio-, lo primero es el concepto, no el mero dato. En la teoría, por tanto, lo decisivo es la mediación del concepto, no la pretendida inmediatez del ente.

Esto nos permite criticar nuevamente al positivismo, esta vez a la inmediatez en la que conciben los «hechos». Estos hechos nunca son lo «dado», sino que suponen mediaciones subjetivas para ser concebidos. Al mismo tiempo, tenemos aquí una crítica de la inmediatez ontológica: Adorno critica también a la fenomenología husserliana y a la ontología heideggeriana la inmediatez en la que ponen al objeto o al ser, descuidando por completo las mediaciones del sujeto. Como decía antes: no hay nada inmediato; todo está mediado.

Finalmente, también hallamos en estas consideraciones una crítica a Hegel, pues tampoco hay nada positivo en el sentido hegeliano: algo que, por efecto de la «negación de la negación», adquiera positividad. Recordemos que, según Hegel:

Lo lógico, según la forma, tiene tres lados: $\alpha$ ) el abstracto o propio del entendimiento; $\beta)$ el dialéctico o racional-negativo; $\gamma$ ) el especulativo o racional-positivo. ${ }^{17}$ dice:

En el agregado de Hegel a este parágrafo de la Enciclopedia

Estos tres lados no constituyen tres partes de la lógica, sino que son tres momentos de todo lo lógico-real, es decir, de todo concepto o de todo lo verdadero en general. Pueden ponerse en conjunto bajo en primer momento, es decir, bajo el entendimiento, y así mantenerlos separados, pero de este modo no son tratados con [arreglo a] su verdad propia. ${ }^{18}$

Veamos el comentario que hacía Alexandre Kojève a este parágrafo clave:

No puede por tanto decirse que el Ser es Identidad $y$ Negatividad: al ser los dos a la vez, separadamente no es ni uno ni otro. El Ser real concreto (revelado) no es

16 DN, p. 149.

17 G.W.F. Hegel, Enciclopedia de las ciencias filosóficas en compendio, tr. Ramón Valls Plana, Madrid: Alianza, 2000, § 79, p. 182.

18 Ibid., p. 183. 
ni Identidad (pura, que es Ser, Sein) ni Negatividad (pura, que es Nada, Nichts), sino Totalidad (que es Devenir, Werden). La Totalidad es entonces la tercera categoría onto-lógica fundamental y universal: el Ser sólo es real o concreto en su totalidad, y toda entidad real concreta es la totalidad de sus elementos constitutivos, idénticos o negadores. El Ser y lo Real se revelan por el pensamiento «positivamente racional» en el aspecto de la Totalidad, y es lo que Hegel califica de «especulativo». ${ }^{19}$

Esta referencia a la «totalidad» es importante puesto que Adorno va a cifrar en ella el carácter de la sociedad capitalista. Esto que Kojève ve como positivo (en el doble sentido de la palabra), para Adorno es negativo (no en sentido dialéctico, sino valorativo). En otras palabras: de la negación de la negación no se desprende nada positivo. No hay tal momento dialéctico en el que el antagonismo se resuelva, se reconcilien los antagonistas y se afirme una nueva positividad. ${ }^{20}$

\section{II.4. LA PREPONDERANCIA DEL OBJETO}

Con estas últimas expresiones nos adentramos en una de las definiciones más importantes de $D N$, me refiero a lo que Adorno denomina «preponderancia del objeto» (Präponderanz des Objekts): «La crítica desarrollada de la identidad avanza a tientas hacia la preponderancia del objeto. El pensamiento identitario es, aunque lo discuta, subjetivista». ${ }^{21}$ Aquí aparece nuevamente el aire de familia entre la dialéctica negativa, la fenomenología husserliana, la ontología heideg-

19 Alexandre Kojève, La dialéctica de lo real y la idea de la muerte en Hegel, tr. Juan José Sebreli, Buenos Aires: La Pléyade, 1972, «La dialéctica de lo real y el método fenomenológico en Hegel», pp. 47-48.

20 Si esto ocurre es por efecto del método, no de la cosa: «Al olvidar a cada nueva fase dialéctica el derecho de la anterior contra la comprensión intermitente de su propia lógica, Hegel prepara el molde de lo que tacha de negación abstracta: una positividad abstracta, es decir, confirmada por la arbitrariedad subjetiva. Ésta brota teóricamente del método, no, como según Hegel debería ser, de la cosa, y se ha expandido como ideología por el mundo tanto como se convierte en auténtico aborto y con ello se convence de su monstruosidad. [...] La negación de la negación no anula a ésta, sino que demuestra que no era lo bastante negativa... Lo negado es negativo hasta que desaparece. Esto aparta decisivamente de Hegel» (DN, p. 154). En uno de los «modelos» que presenta Adorno en su $D N$, a saber, en el segundo, titulado «Espíritu del mundo e historia de la naturaleza. Excurso sobre Hegel», nuestro filósofo expresa: «lo que en él [i. e., en Hegel] se llama síntesis», este momento de superación (Aufhebung) donde la negación produce positividad, «no es simplemente la cualidad sin más nueva, brotada de la negación determinada, sino el regreso de lo negado; el proceso dialéctico siempre es también un recurso a lo que cayó víctima de la progresión del concepto: la concreción progresiva de éste es su autocorrección» (Ibid., p. 306. La cursiva es nuestra).

21 Ibid., p. 174. 
geriana y el positivismo (siempre, claro está, teniendo en cuenta las diferencias que he apuntado más arriba).

Con este reconocimiento a la preponderancia del objeto, modificamos la concepción tradicional de la «cosa», de ese individuo o particular que a duras penas podía ofrecer algo más que ser un «caso» de un universal-concepto (o regla, en Kant) puesto por el sujeto cognoscente. En la dialéctica negativa lo particular se libera de la subsunción en lo universal y despliega, gracias a una «mirada microscópica», la totalidad social objetiva que le dio existencia. Estamos frente a lo que se denomina «particular concreto», otra herejía para el hegelianismo. Como expresa Buck-Morss:

Lo distintivo de la aproximación de Adorno era no sólo su hegeliana definición de la realización dialéctica entre lo particular y lo general, sino el hecho de encontrar, a diferencia de Hegel, lo general dentro de las características de la superficie misma de lo particular, y la verdad dentro de aquello en apariencia más insignificante, atípico o extraño. En la encrucijada de dos posiciones aparentemente contradictorias, al insistir en la relación dialéctica del fenómeno con la totalidad y al mismo tiempo en la necesidad del análisis microcósmico, Adorno fundó su concepto de «lo particular concreto». ${ }^{22}$

Esta expresión choca con aquella hegeliana de lo «universal concreto», ese universal que ha perdido su carácter «abstracto» (en el sentido de «vacío» e «indeterminado»), característico del primer momento inmediato de la dialéctica. Y ha perdido ese carácter abstracto gracias a la negatividad que lo ha determinado progresivamente, que lo ha particularizado. El universal concreto hegeliano es concreto, justamente, por la mediación negativa de lo particular. Aquí se nos presenta lo contrario: el particular es concreto en la medida en que contiene siempre-ya lo universal como totalidad social. Continúa Buck-Morss:

Lo particular no constituía «un caso de lo general», no podía ser identificado por su ubicación dentro de una categoría general, ya que su significación residía más en su contingencia que en su universalidad. Además (y esto era lo que separaba su teoría [i. e., la de Adorno] del nominalismo) lo particular no era idéntico a sí mismo. Era algo más que la tautológica proposición «rosa es una rosa», por su relación mediada con la sociedad. Como las mónadas de Leibniz, cada particular era único, pero cada uno contenía una imagen del todo, una «imagen del mundo»,

22 S. Buck-Morss, op. cit., p. 161. «Totalidad» aquí es entendida según la «significación marxiana de la estructura socioeconómica de relaciones que caracterizaba el orden burgués.» Ibid., p. 160. 
lo que dentro de un marco marxista significaba una imagen de la estructura social burguesa. $^{23}$

La «preponderancia del objeto» es, por lo tanto, un principio metodológico fundamental en la investigación filosófica y social. De alguna manera, hay que «entrar dentro del objeto», como expresa Benjamin, ${ }^{24}$ para liberar la trama social que se encuentra en su interior.

Pero el concepto de «preponderancia del objeto» contiene más sentidos. Significa, por ejemplo, que «ser también objeto forma parte del sentido de la subjetividad; no igualmente del sentido de la objetividad ser sujeto». ${ }^{25}$ Todo sujeto es ya una clase de objeto, pero no todo objeto es también sujeto. En cuanto a la inmediatez en la que aparentemente quedaría el objeto, una vez reconocida su prelación con respecto al sujeto, aclara Adorno: «No es que la objetividad sea algo inmediato, que haya que olvidar la crítica al realismo ingenuo. La prelación del objeto significa la progresiva diferenciación cualitativa de lo en sí mediado, un momento de la dialéctica que no está más allá de ésta pero que se articula en ella». ${ }^{26} \mathrm{El}$ objeto no deja de ser una realidad mediada por el sujeto a pesar de tener preponderancia sobre éste. De esto tiene que dar cuenta también la dialéctica negativa. Otro sentido de la Präponderanz, -esta vez en el terreno lógico formal-: «lo no cogitativo es condición lógico-inmanente del pensamiento. Propiamente hablando, la cópula, el es, siempre contiene ya, según el modelo del juicio existencial, la objetualidad (Gegenständlichkeit)». ${ }^{27}$ Finalmente, y volviendo sobre la cuestión de la pretendida inmediatez del objeto, Adorno nos dice: «La prelación del objeto [Der Vorrang des Objekts], en cuanto algo sin embargo él mismo mediado, no acaba con la dialéctica sujeto-objeto. La inme-

23 Ibid.,p. 167. Todo esto está directamente relacionado con la «mirada microscópica» de Benjamin que trae a colación Buck-Morss: «Como herramienta para el conocimiento filosófico, [la mirada microscópica] era un medio para que cada mínima particularidad del objeto liberara una significación que disolvía su apariencia deificada y la revelaba como algo más que simplemente idéntica a sí misma. Al mismo tiempo, el conocimiento liberado permanecía adherido a lo particular en lugar de sacrificar su especificidad material en un nivel de abstracta generalización ahistórica» (Ibid., p. 162).

24 Citado en: Ibid., p. 170.

25 DN, pp. 174-175.

26 Ibid., p. 175. Más adelante Adorno afirma: «Sólo porque está por su parte mediado, y por tanto no es lo radicalmente otro del objeto que es lo único que legitima al sujeto, puede éste comprender en general la objetividad». Ibid., p. 176. Tanto objeto como sujeto se encuentran mutuamente mediados el uno por el otro. Es gracias a ello que el objeto no es algo inmediato (en el sentido del realismo ingenuo) y que el sujeto, a su vez, no goza de dominio absoluto sobre el objeto, pues también aquél está mediado por éste.

27 Ibid., p. 175n. 
diatez está más allá de la dialéctica tan poco como la mediación». ${ }^{28} \mathrm{Y}$ pocas páginas más adelante completa:

Lo que la cosa misma pueda significar no está positiva, inmediatamente dado; quien quiera conocerlo debe pensar más, no menos, que el punto de referencia de la síntesis de lo múltiple, que en lo más profundo no es ningún pensamiento en absoluto. Sin embargo, la cosa misma no es de ningún modo un producto del pensamiento; más bien lo no-idéntico [das Nichtidentische] a través de la identidad. ${ }^{29}$

\section{MEDIACiÓN E INMEDIATEZ}

En esta segunda sección del trabajo, ofreceré una serie de críticas a la posición de Adorno en $D N$ con respecto a lo inmediato. Para ello repasaré, en primer lugar, cuál es esa posición, basándome en lo expuesto hasta aquí. En segundo lugar, desarrollaré los argumentos que permiten realizar una defensa de lo inmediato, tomando como apoyo las propias definiciones de $D N$. Por último, evaluaré si esta defensa de lo inmediato puede considerarse una recaída en la positividad o si, por el contrario, como sostendré más adelante, podría estar orientada hacia una radicalización de la negatividad dialéctica.

\section{III.1. LA CRÍTICA DE LA INMEDIATEZ}

En la primera parte de este trabajo he tenido ocasión de exponer sucintamente algunas ideas críticas de Adorno relacionadas con el par tradicional de conceptos mediación/inmediatez. Una advertencia metodológica de nuestro autor nos puso sobre aviso de confundir el ente, el algo, punto de partida de toda la dialéctica negativa, con lo presuntamente «dado» $\mathrm{o}$ «inmediato»: «Puesto que el ente no es inmediatamente, sino sólo a través del concepto, habría que comenzar por el concepto, no por el mero dato». ${ }^{30}$ Interpretamos esta afirmación de la siguiente forma: si en el orden ontológico lo primero es el ente, en el orden gnoseológico, por el contrario, lo primero es el concepto. Concluí con la afirmación de que en la teoría lo decisivo es la mediación del concepto, no la pretendida inmediatez del ente. En este sentido, lo inmediato será para Adorno el signo de lo reificado, de la ideología burguesa en acción. La teoría crítica será el intento de desmitificar lo inmediato, de develar su carácter mediado y así evidenciar su contingencia y, con ella, la posibilidad de su transformación.

28 Ibid., p. 177.

29 Ibid., p. 179.

30 DN, p. 149. 


\section{III.2. DEFENSA DE LO INMEDIATO}

En el marco de esta concepción particular de la inmediatez, toda defensa de lo inmediato adquiere características conservadoras, pues se trataría, en definitiva, de la defensa de lo existente, del status quo, de la realidad comprendida «más acá» de las mediaciones sociales, históricas, que la hicieron posible. ${ }^{31}$ Para autores como Lukács y Adorno una defensa de lo inmediato sería epistemológicamente incorrecta, ideológicamente reaccionaria, y ontológicamente falsa. La asociación de lo inmediato con los «hechos» del positivismo o con el «ser» de la ontología heideggeriana alcanza para darnos cuenta del carácter conservador y mistificador de toda defensa de lo inmediato en el conocimiento, en la teoría social y en la realidad misma.

En esta sección del trabajo quiero señalar la posibilidad de una defensa de lo inmediato en la dimensión político-social, que no se comprometa con posiciones filosóficas positivistas, fenomenológicas (en el sentido de Husserl) u ontológicas (en el sentido de Heidegger). Una defensa que no implique, por lo tanto, un giro conservador con respecto a la tradición frankfurtiana (incluido Lukács), sino que, por el contrario, enmarcada en la dialéctica negativa, pueda profundizar la crítica de lo existente en función de un imperativo transformador de la realidad social. Creo que una defensa de lo inmediato de este tipo está orientada hacia una radicalización de la negatividad dialéctica y no hacia un reforzamiento de la positividad capitalista.

La clave de una defensa de este tipo la ofrece el propio Adorno en $D N$. Es por ello que sostengo el carácter inmanente de esta defensa de lo inmediato que realizo aquí respecto de la dialéctica negativa -y de la tradición frankfurtiana. Hay un pasaje de $D N$ especialmente relevante al momento de comprender cuáles son los argumentos que ofrece Adorno para rechazar todo posicionamiento «inmediatista» con respecto al saber en general y a la teoría social en particular, pero que al mismo tiempo revelan la necesidad de lo inmediato con respecto a las mediaciones dialécticas. Lo cito in extenso:

Pero la universalidad de la mediación no es ningún título legal para nivelar con relación a ella todo lo que se halla entre el cielo y la tierra, ${ }^{32}$ como si mediación

31 «Cuanto menos sufran la inmediatez humana los omnipresentes mecanismos de mediación del intercambio, tanto más se apresurará una complaciente filosofía a aseverar que posee en lo inmediato el fundamento de las cosas; y este espíritu ha triunfado sobre la especulación, tanto en las ciencias cósicas como en sus adversarios» (esto es, tanto en el positivismo como en la fenomenología husserliana y la ontología existencial de Heidegger). Th. W. Adorno, Tres estudios sobre Hegel, ed. cit., «La sustancia experiencial» (1958), p. 79.

32 Aquí resuena una conocida frase de la Ciencia de la Lógica de Hegel que reza así: «[...] nada hay en el cielo, en la naturaleza, en el espíritu o donde sea, que no contenga al mismo tiempo la inmediación y la mediación, así que estas dos determinaciones se presentan 
de lo inmediato [Vermittlung des Unmittelbaren] y mediación del concepto [Vermittlung des Begriffs] fueran lo mismo. Al concepto la mediación le es esencial, él mismo es, según su constitución, inmediatamente la mediación; la mediación de la inmediatez, sin embargo, determinación de la reflexión, significativa sólo en relación con lo a ella opuesto, lo inmediato. Si ya no hay nada que no esté mediado, tal mediación, como Hegel subrayó, necesariamente se refiere siempre a algo mediado sin lo cual ella por su parte tampoco existiría. Por el contrario, que no haya nada mediado sin mediación tiene un carácter exclusivamente privativo y epistemológico: expresión de la imposibilidad de sin mediación determinar el algo, apenas más que la tautología de que pensar en algo es precisamente pensar. A la inversa, sin el algo no quedaría ninguna mediación. Ni en la inmediatez se encuentra su ser-mediado [Vermitteltsein] ni en la mediación algo inmediato que sería mediado. Hegel descuidó esta distinción. La mediación de lo inmediato afecta a su modus: al saber de ello y a los límites de tal saber. La inmediatez objetiva, no una modalidad, una mera determinación del cómo para una consciencia: su concepto de inmediatez se refiere a lo que no puede ser eliminado por el concepto de ésta. La mediación no dice de ningún modo que todo se absorba en ella, sino que postula lo que es mediado por ella, algo no absorbible; pero la inmediatez misma representa un momento que no necesita del conocimiento, de la mediación, del mismo modo que ésta precisa de lo inmediato. ${ }^{33}$

Varias proposiciones podemos extraer de este pasaje:

1) «Mediación de lo inmediato» y «mediación del concepto» son dos cosas distintas, pues:

a) el concepto es ya mediación («mediación del concepto» es lo mismo que, «el concepto, que es mediación»), y

b) la mediación de la inmediatez es una determinación de la reflexión -que tiene sentido sólo en relación con lo a ella opuesto, lo inmediato- (la «mediación de la inmediatez» es «mediación de lo inmediato»).

2) Mediación e inmediatez se suponen mutuamente, aunque en sentidos distintos (ontológico y epistemológico):

como unidas e inseparables [...]». G.W.F. Hegel, Ciencia de la Lógica, tr. Augusta y Rodolfo Mondolfo, Buenos Aires: Ediciones Solar, 1993, vol. 1, p. 88. Cf. Th. W. Adorno, Tres estudios sobre Hegel, ed. cit., «La sustancia experiencial» (1958), p. 84: «[...] es tan difícil hablar de la mediación sin algo inmediato como, a la inversa, encontrar algo inmediato que no esté mediado. Pero él [i.e., Hegel] no contrapone rígidamente por más tiempo ambos momentos: se producen y reproducen recíprocamente, se forman de nuevo a cada nivel y únicamente en la unidad del todo se desvanecen, reconciliados».

33 DN, pp. 164-165. 
a) toda mediación supone necesariamente algo mediado, esto es, algo inmediato que ha sido mediado por esa mediación. No existe mediación sin inmediatez;

b) pero no hay nada inmediato que no requiera mediaciones, aunque no en un sentido ontológico sino epistemológico: no se puede pensar sin mediaciones.

3) La mediación de lo inmediato afecta al saber; la inmediatez se refiere a un algo real que no puede ser subsumido en el concepto que la media:

a) en el conocimiento la mediación postula lo inmediato (pues es mediación de algo de por sí no mediado);

b) pero la inmediatez no necesita del conocimiento, de la mediación del concepto; en cambio ésta sí precisa de lo inmediato (de lo contrario sería conocimiento de sí misma y no de algo que ella pretende mediar, hacer conceptualizable, cognoscible).

Si tomamos la segunda proposición extraída, probablemente tengamos una buena síntesis de lo que quiero destacar: mediación e inmediatez se suponen mutuamente, aunque en sentidos distintos (ontológico y epistemológico): la inmediatez supone mediación en el campo epistemológico o gnoseológico, mientras que la mediación supone inmediación en el campo ontológico. En otras palabras, la mediación tiene prioridad en el conocimiento pero en la realidad lo inmediato es siempre anterior a la mediación: «la inmediatez misma representa un momento que no necesita del conocimiento, de la mediación, del mismo modo que ésta precisa de lo inmediato». ${ }^{34}$

En virtud de lo dicho, podemos leer la «preponderancia del objeto» que, según Adorno, se resume en la convicción de que «lo no cogitativo es condición lógico-inmanente del pensamiento», ${ }^{35}$ de una manera decisivamente diferente: la preponderancia del objeto implica la preponderancia de lo inmediato. Toda mediación actúa sobre un algo no cogitativo no mediado. Como indica Ciro Mesa con respecto a $D N$ :

Si bien por un lado el postulado de un momento de inmediatez fuera de la mediación universal establecida por la historia es condición de posibilidad del pensar crítico, por otro le plantea también una nueva exigencia: asumir la consciencia de

34 Ibid., p. 165.

35 Ibid., p. 175n. 
la prioridad del objeto como un «momento articulador de la dialéctica». [...] La prioridad del objeto recuerda al pensamiento que se debe al impulso de la cosa, cuya inmediatez no-idéntica lo sobrepasa. A través de ese recuerdo la dialéctica negativa critica al pensar identificante y busca aplacar la furia del concepto volviéndolo contra sí mismo. ${ }^{36}$

Esta «inmediatez no-idéntica» es ontológicamente independiente de cualquier mediación conceptual cognitiva que se aplique a comprenderla aunque, claro está, una vez que ha sido mediada no es más independiente (en el campo del conocimiento). ¿Esto significa que la inmediatez está fuera de la dialéctica? De ninguna manera, como el propio Adorno lo indica: «La prelación del objeto, en cuanto algo sin embargo él mismo mediado, no acaba con la dialéctica sujeto-objeto. La inmediatez está más allá de la dialéctica tan poco como la mediación». ${ }^{37}$ El reconocimiento de la dialéctica entre mediación e inmediatez nos compromete a asumir tanto lo uno como otro: lo inmediato no niega la mediación, simplemente la requiere para que podamos comprenderlo; la mediación no niega lo inmediato, más bien lo supone pues sobre ello actúa.

\section{RADICALIZACIÓN DE LA DIALÉCTICA NEGATIVA (CONCLUSIONES)}

Pero, habida cuenta de los argumentos expuestos hasta aquí, ¿en base a qué podemos decir que una defensa de lo inmediato - que podemos encontrar ya en $D N$ - está orientada hacia una «radicalización de la negatividad dialéctica»? Parece más bien lo contrario: lo inmediato tal como lo he presentado más arriba aparece como una positividad sustancial, una realidad que se afirma en y por sí misma, con total independencia -en lo ontológico- respecto de la actividad mediadora del sujeto. ${ }^{38}$ No obstante, sostengo lo contrario: una defensa de lo

36 Ciro Mesa, «Mediación e intercambio. Sobre la relación entre crítica y conocimiento, filosofía de la historia y crítica social en Adorno», en: Anales del Seminario de Metafísica, ${ }^{\circ}$ 30, 1996, Servicio de Publicaciones, Universidad Complutense de Madrid, p. 217.

37 DN, p. 177.

38 Podríamos preguntarnos aquí si no estamos, acaso, repitiendo el esquema gnoseológico clásico, el del idealismo pero también el del empirismo y el positivismo, a saber, el esquema sujeto/objeto. Haríamos bien, en este punto, volver sobre una de operaciones conceptuales de $D N$ que desarrollamos en la primera parte de este trabajo. Nos referimos a la resignificación de los dualismos tradicionales; puntualmente, al de sujeto-objeto. Véase: ibid., p. 167. Sujeto-objeto son, para Adorno, mutuamente no-idénticos: cada uno es lo que el otro no es. Su relación es, como dijimos anteriormente, dialéctica y negativa: «se constituyen mutuamente tanto como, en virtud de tal constitución, se separan». No se trata de positividades plenamente constituidas una independientemente de la otra: «Ni el sujeto es nunca en verdad enteramente sujeto, ni el objeto nunca enteramente objeto» (Ibid., p. 168). Siempre encontraremos un resto de subjetividad en el objeto, así como también los «mecanismos objetivos de mediación» que se prolongan en el sujeto. 
inmediato continúa la defensa adorniana de lo no-idéntico (das Unidentische), la profundiza. Sostiene la irreductibilidad de lo real a las mediaciones conceptuales del sujeto; niega la indispensabilidad de la actividad mediadora del sujeto para que la realidad social se constituya. Parafraseando las primeras líneas de $D N$ (sustituimos «el algo» por «lo inmediato»): «Lo inmediato en cuanto sustrato cogitativamente necesario del concepto, incluido el del ser, es la abstracción extrema, pero que ningún proceso ulterior de pensamiento elimina, de lo cosal no idéntico con el pensar». ${ }^{39}$

Una objeción que se me podría hacer a este respecto es que estoy olvidando que la «mediación» en Adorno no significa tan sólo la mediación del objeto por el sujeto - no hay objeto de conocimiento que no esté completamente mediado por las categorías del sujeto-, sino también, como vimos en la primera parte del trabajo, la mediación del sujeto por el objeto: los modos en los que la subjetividad es constituida por la totalidad social. Según esta observación -con la que por cierto acuerdo plenamente-, si criticamos la enfática defensa que desarrolla Adorno (y con él Kant, Hegel, Marx, Lukács, etc.) de la mediación, estaríamos criticando tanto la mediación como conceptualización subjetiva, como también la mediación del sujeto por parte de la sociedad (o de un modo de producción social, específicamente). Esta operación doble que realiza Adorno en $D N$ la resume muy bien Ciro Mesa en las siguientes líneas:

Contra el supuesto de cualquier forma de identidad originaria sujeto-objeto o de la posibilidad de un acceso cognitivo a la inmediatez, Adorno sienta el carácter indisoluble de la mediación. Pero no sólo de la del objeto por el sujeto, sino también la del sujeto por el objeto, evitando así que el propio carácter mediador de la subjetividad sea absolutizado. ${ }^{40}$

En otras palabras, si el mediador (el sujeto) se encuentra a su vez mediado por lo que él media (el objeto), entonces su mediación no es absoluta. De esta forma Adorno evitaría la crítica que podríamos formularle de que, tal como el idealismo absoluto, reduce el todo de la realidad a mediaciones subjetivas. Su defensa acérrima de la mediación lo llevaría a una recaída de la dialéctica negativa en la filosofía de la identidad: ser es ser-mediado (por un sujeto); casi una rehabilitación del idealismo de Berkeley, o, al menos, una supervivencia del idealismo absoluto hegeliano.

Pero la complementación de la tesis de la necesidad de la mediación que ofrece la mediación del sujeto por el objeto, ¿acaba realmente con las sospechas de que la $D N$ concluye en alguna forma de idealismo? Mi respuesta es negativa por el siguiente motivo: el «objeto» que media al sujeto -como tuve oportunidad

40 C. Mesa, op. cit., p. 215. 
de aclarar anteriormente- no es una mera «cosa» sino más bien la «totalidad social» que le ha dado lugar a esta. Por lo tanto, cuando Adorno habla de la mediación del sujeto por el objeto, lo que está sosteniendo es la mediación del sujeto por la sociedad. Ahora bien, ¿no es acaso la «sociedad» un conjunto de relaciones intersubjetivas (sean cuales fueren esas relaciones y el modo en el que se establecen)? Cuando decimos «objeto», entonces, de acuerdo con los recaudos señalados inclusive por Adorno, ¿no estamos hablando fundamentalmente de relaciones sujeto-sujeto y de las relaciones que esos sujetos, conjuntamente, establecen con los objetos que producen socialmente y con el medio objetivo «natural»? O bien el «objeto» que media los sujetos es una cosa lisa y llana, algo inmediato por lo tanto, o bien es, como dice Adorno, la totalidad social intersubjetiva, con lo cual llegamos a la paradójica conclusión de que lo que media al sujeto son los demás sujetos. ¿No es esto, acaso, lo que decía Hegel cuando hablaba del «espíritu absoluto»? El espíritu, ese yo que es el nosotros y ese nosotros que es el yo, ${ }^{41} \mathrm{el}$ «pueblo como totalidad de ciudadanos autoconscientes», como define Rubén Dri, ${ }^{42}$ ese «sujeto plural y uno a la vez», según interpreta con claridad Ramón Valls Plana, ${ }^{43}$ el espíritu hegeliano así entendido es esa totalidad social de Adorno que constituye y, a su juicio, también oprime a los sujetos a través de sus múltiples e imbricadas mediaciones.

Creo que un modo de salvar a la dialéctica negativa de esta traducción idealista de la mediación del objeto es liberándola de la tarea de defender la necesidad de la mediación. Esto es, reconociendo una instancia inmediata que, al posicionarse necesariamente por fuera de las mediaciones que son siempre subjetivas, o más bien, inter-subjetivas, nos permita ejercer una defensa de lo no-idéntico esta vez, de lo irreductible al concepto subjetivo. Es por ello que sostengo que una defensa de lo inmediato continúa y radicaliza - de modo inmanente-el programa de la dialéctica negativa, cuyo punto de partida es, en el nivel ontológico, el «algo» no-idéntico con el pensar que lo piensa.

Eduardo Assalone es Becario de Posgrado Tipo I del Consejo Nacional de Investigaciones Científicas y Técnicas (CONICET), con lugar de trabajo en el Departamento de Filosofía de la Facultad de Humanidades de la Universidad Nacional de Mar del Plata, Argentina.

41 G.W.F. Hegel, Fenomenología del espíritu, ed. cit., p. 113.

42 Rubén Dri, La odisea de la conciencia moderna. Hermenéutica del capítulo VI de la Fenomenología del espíritu, Buenos Aires: Biblos, 1999, p. 19.

43 Ramón Valls Plana, Del yo al nosotros. Lectura de la Fenomenología del Espíritu de Hegel, Barcelona: Estela, 1971, p. 76. 
Línea de investigación:

Filosofía social y política de G.W.F. Hegel, su contexto histórico y su impacto en las discusiones actuales sobre la relación entre Estado y sociedad civil.

Publicaciones recientes:

ASSALONE, E. Y MISSERI, L. (comps.), El giro subjetivista de la filosofía moderna. Perspectivas históricas y debates contemporáneos, Mar del Plata: Cátedra de Filosofía Moderna, 2010.

ASSALONE, E. "Hegel y la fundamentación burocrática de la filosofía. La relación entre la filosofía y el Estado en los Principios de la Filosofía del Derecho de Hegel”, en: Revista Filosofía UIS, Vol. 10, No. 2 del año 2011, Escuela de Filosofía de la Universidad Industrial de Santander, Colombia. Trabajo aceptado. En prensa.

Dirección electrónica: queridokant@yahoo.com.ar 